\title{
EVALUATION OF THE USE OF ARTIFICIAL NEURAL NETWORKS FOR THE SIMULATION OF HYBRID SOLAR COLLECTORS
}

\author{
Jorge Facão, Szabolcs Varga and Armando C. Oliveira* \\ Faculty of Engineering - University of Porto \\ Department of Mechanical Engineering and Industrial Management \\ Rua Dr. Roberto Frias, 4200-465 Porto, Portugal \\ acoliv@fe.up.pt
}

\begin{abstract}
In the last decade, artificial neural networks (ANNs) have been receiving an increasing attention for simulating engineering systems due to some interesting characteristics such as learning capability, fault tolerance, speed and non-linearity. This paper describes an alternative approach to assess two types of hybrid solar collector/heat pipe systems (plate heat pipe type and tube heat pipe type) using ANNs.

Multiple Layer Perceptrons (MLPs) and Radial Basis Networks (RBFs) were considered. The networks were trained using results from mathematical models generated by Monte Carlo simulation. The mathematical models were based on energy balances and resulted in a system of non-linear equations. The solution of the models was very sensitive to initial estimates, and convergence was not obtained under certain conditions. Between the two neural models, MLPs performed slightly better than RBFs. It can be concluded that similar configurations were adequate for both collector systems. It was found that ANNs simulated both collector efficiency and heat output with high accuracy when "unseen" data were presented to the networks. An important advantage of a trained ANN over the mathematical models is that convergence is not an issue and the result is obtained almost instantaneously.
\end{abstract}

\section{INTRODUCTION}

Heat pipe solar collectors can either be of the flat-plate type or of the evacuated-tube type. The thermal performance of evacuated-tube collectors is described in reference [1], while flat-plate heat pipes have been studied by several authors [2-5].

In order to predict solar collector performance, numerical models can be used. Traditional regressive models are based on energy balances that can be solved either numerically or analytically. Some of the drawbacks are that they use a large number of parameters, empirical correlations for heat transfer and sometimes there is the possibility of no convergence.

Neural networks are widely accepted as a technique offering an alternative way to tackle complex and ill-defined problems. They can learn from examples, are fault tolerant in the sense that they are able to handle noisy and incomplete data, are able to deal with non-linear problems, and once trained can perform prediction at very high speed [6]. It has a wide variety of applications: pattern recognition, decisionmaking, system control, information processing, symbolic mathematics, computer-aided instruction, speech recognition, vision and robotics. Artificial neural network approaches have been applied to many thermal systems [7] and also renewable energy systems [8].

The primary objective of this work was to evaluate whether ANNs present any practical advantage over a traditional approach in predicting the thermal performance of two different types of solar collectors, while providing at least the same degree of accuracy. Training of the ANN was accomplished by using results of the regressive model.

\section{COLLECTOR DESIGN}

Two types of hybrid heat pipe solar collectors were studied: plate heat pipe and tube heat pipe - see Fig.1. Both collectors are supplied with a double glazing cover on top, at a distance of $12 \mathrm{~mm}$ from the metal plate; collector surface is equal to $2.4 \mathrm{~m}^{2}$. The collectors have a hybrid heat input. Besides solar energy, a hot gas, coming from a gas burner (located at collector entrance), is circulated below the metal plate - see Fig.1 and Fig.2. Useful heat is transferred to a stream of water using heat pipes (tubular or plate shape) in order to minimise the temperature gradient and maximise the heat transfer between the input and output points of the system. This type of collector was developed for use in hybrid power generation cycles [9]. Table 1 shows the solar collector characteristics.

Table 1. Solar collector characteristics.

\begin{tabular}{|l|l|}
\hline Number of heat pipes & 20 \\
\hline Evaporator length & $1.70 \mathrm{~m}$ \\
\hline Condenser length & $50 \mathrm{~mm}$ \\
\hline Adiabatic length & $150 \mathrm{~mm}$ \\
\hline Tube spacing & $70.9 \mathrm{~mm}$ \\
\hline Plate thickness & $2 \mathrm{~mm}$ \\
\hline Tube diameter & $8 \mathrm{~mm}$ \\
\hline Back insulation thickness & $22 \mathrm{~mm}$ \\
\hline Cover emissivity & 0.88 \\
\hline Cover transmissivity & 0.87 \\
\hline Plate emissivity & 0.16 \\
\hline Plate absorptance & 0.95 \\
\hline Tilt angle & $38^{\circ}$ \\
\hline
\end{tabular}




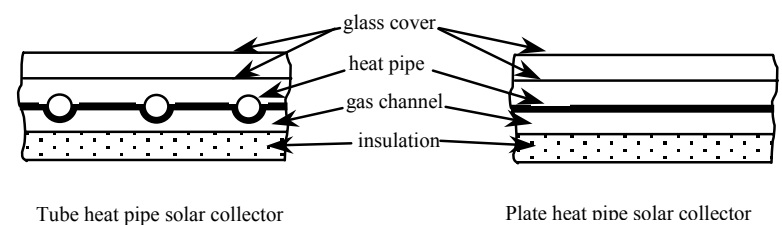

(a) Types of heat pipe solar collectors.

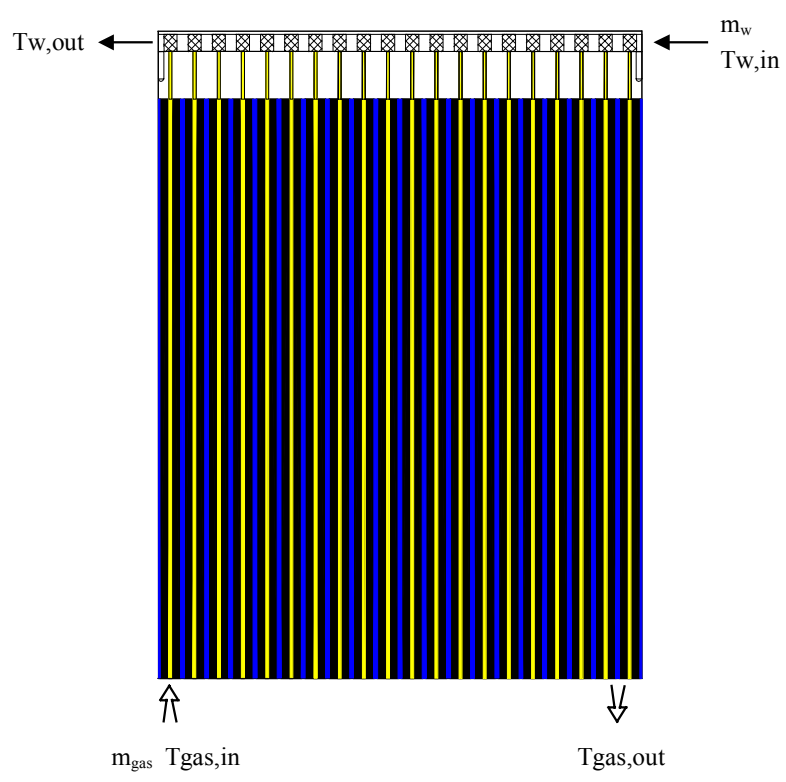

Fig. 1. (b) Hybrid heat pipe solar collector.

\section{MATHEMATICAL MODEL}

Two types of models were applied to simulate the heat transfer in the solar collectors. The first type was based on the conservation of energy law and the second was a "black box" approach using ANN. Collector performance was estimated using two parameters, the thermal efficiency, $\eta_{\text {collector }}$, and the total heat transferred by the hybrid system, $Q$. The latter was evaluated as the useful heat transferred to the water stream in the condenser. The thermal efficiency can be defined as:

$$
\eta_{\text {collector }}=\frac{Q}{I A+Q_{\text {gas }}}
$$

where $Q_{\text {gas }}$ is the heat transferred from combustion gas to the collector plate and obtained from:

$$
Q_{\text {gas }}=m_{\text {gas }} c_{p}\left(T_{\text {gas }, \text { in }}-T_{\text {gas }, \text { out }}\right)
$$

\section{Models based on conservation of energy}

Two approaches with different complexity were developed based on the conservation of energy law for the two cases: a simpler one for the plate type collector and a more complex one for the tube type collector. The main objective of this was to evaluate the effect of model complexity on the optimal ANN architecture and its predictive power.
- $\quad$ Plate heat pipe solar collector

The major simplification for the plate type design was that the temperature in the heat pipe was considered to be uniform and equal to the saturation temperature of the working fluid, $T_{\text {sat }}$. Normally heat pipes are modelled with thermal resistances (see next subsection), but the heat pipe resistances could be very small so that in many cases they can be neglected [4]. It was also assumed that the temperature variation inside the glass covers was negligible. In order to calculate the heat transfer inside the hybrid collector the following equations can be obtained: energy balance on first glass and second cover, energy balance on collector side of heat pipe, heat flux from the gas to the plate, heat transfer from the combustion gas to the heat pipe, energy balance on the condenser surface and overall heat balance. Detailed mathematical formulation of these balances is given in [10].

The resulting set of non-linear equations was simultaneously solved for the glass temperatures, working fluid saturation temperature, the gas and water outlet temperatures, and the heat fluxes through the gas and collector side of the evaporator section. The heat transfer coefficients on the collector side were determined using empirical correlations for natural convection in horizontal cavities [11]. The external heat transfer coefficient $\left(h_{\text {wind }}\right)$ was calculated as a function of the wind speed according to [12]. $h_{\text {gas }}$ and $U_{\text {cond }}$ were taken as constant using typical values. The solution of the non-linear set of equations was obtained by the Newton-Raphson's method [13].

\section{- Tube heat pipe solar collector}

Uniform temperature in the glass covers was also considered for the tubular type design. However, the assumption of uniform temperature distribution on the collector plate was no longer valid, because of the heat transfer between heat pipes. A one dimensional temperature variation perpendicular to the tube axis was considered.

The heat transfer over the two glass covers was identical to the previous model. The energy balance on the collector plate was evaluated considering a differential volume of length $\mathrm{dx}$ (with $\mathrm{x}$ perpendicular to the tube axis) yielding a second-order differential equation:

$$
S+q_{g a s}-h_{p-c 1}\left(T-T_{c 1}\right)-\sigma \frac{T^{4}-T_{c 1}^{4}}{\frac{1}{\varepsilon_{c}}+\frac{1}{\varepsilon_{p}}-1}-\frac{d}{d x}\left(-\lambda \delta \frac{d T}{d x}\right)=0
$$

In order to solve Eq. (3), the domain was discretised using a finite-difference scheme with one hundred finite-difference volumes. Knowing the plate temperature distribution, it is possible to calculate the useful energy per unit length of heat pipe with:

$$
Q^{\prime}=-\left.2 \lambda \delta \frac{d T}{d x}\right|_{x=\frac{c-d_{e x t}}{2}}+d_{e x t}\left[S-h_{p-c 1}\left(T_{t}-T_{c 1}\right)-\sigma \frac{T^{4}-T_{c 1}^{4}}{\frac{1}{\varepsilon_{c}}+\frac{1}{\varepsilon_{p}}-1}+\frac{\pi}{2} q_{g a s}\right]
$$


In Eq. (4), Q' indicates the heat transferred to the heat pipe evaporator. In this case, it was assumed that there was a temperature distribution inside the heat pipe. The thermal balance in the heat pipes is usually estimated using an electric circuit analogy as:

$Q^{\prime}=\frac{T_{t}-T_{\text {sat }}}{\sum R_{\text {heatpipe }}}$

In the denominator part of Eq. (5), $\Sigma R_{\text {heatpipe }}$ represents the total thermal resistance. For a detailed discussion of the individual thermal resistances, the reader is referred to Dunn and Reay [14] or Peterson [15]. In this work typical values were chosen.

The thermal balances in the gas channel and in the condenser were calculated using the equations for the plate collector with the difference that $h_{\text {gas }}$ and $U_{\text {cond }}$ were determined using empirical correlations [16] and [17]. The numerical model was implemented in the EES (F-Chart software, USA), [18], computer environment.

\section{- Neural network model}

A detailed discussion of existing neural network models is out of the scope of this paper. Here only some of the relevant issues are presented. For details the reader is referred to [19], [20] and [21]. Two types of feed forward ANNs are widely used in engineering for simulation proposes: multi-layer perceptrons (MLP) and radial basis functions (RBF). ANNs are typically made up of many interconnected processing units, called neurons. Detailed representation of a typical neuron is shown in Fig.3.

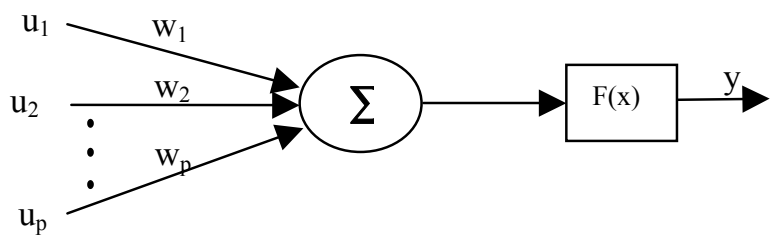

Fig. 3. Artificial neuron.

The information $\left(u_{i}\right)$ enters the neuron through $p$ input connections after being multiplied by a "synaptic weight $\left(w_{i}\right)$. Mathematically the information processing can be written as:

$y=F\left(\sum_{i=1}^{p} w_{i} u_{i}\right)$

There are several choices for the form of the activation function $(F)$. Any bounded increasing function can be applied. However due to some attractive properties (e.g. differentiability, saturation, etc.) usually sigmoid shaped functions (e.g. hyperbolic tangent) are used.

By itself, a single processing element has a very limited predictive power. Its capacity emerges from arranging many of these individual units into a strongly interconnected parallel architecture [20] such as an
MLP architecture shown in Fig. 4. In the input layer, the independent variables are presented to the network. They are not artificial neurons, because there is no data processing, only branching. The response variables are "collected" at the output layer. Those layers (usually one) that are not visible to the exterior are called hidden layers.

One of the most important properties of ANN's is its capability of "learning" from examples where for a given set of inputs the desired outputs are available. The learning or training process is achieved by adjusting the weights $(\mathbf{w})$ in a way that the network output results in a sufficiently small error when compared to the target values. Another interesting property is that they can generalise or, in other words, they can produce accurate outputs for inputs that have not been seen before.

Mathematically the training process is a non-linear optimisation problem. One seeks for $\mathbf{w}$ that minimises an objective (cost) function. The objective function is an error measure between the predicted, $y$, and target outputs, t, e.g. the mean square error:

$$
M S E=\frac{1}{n} \sum_{p=1}^{N p} \sum_{j=1}^{n_{s}}\left(t_{j p}-y_{j p}\right)^{2}
$$

For available training techniques the reader is referred to [20-22].

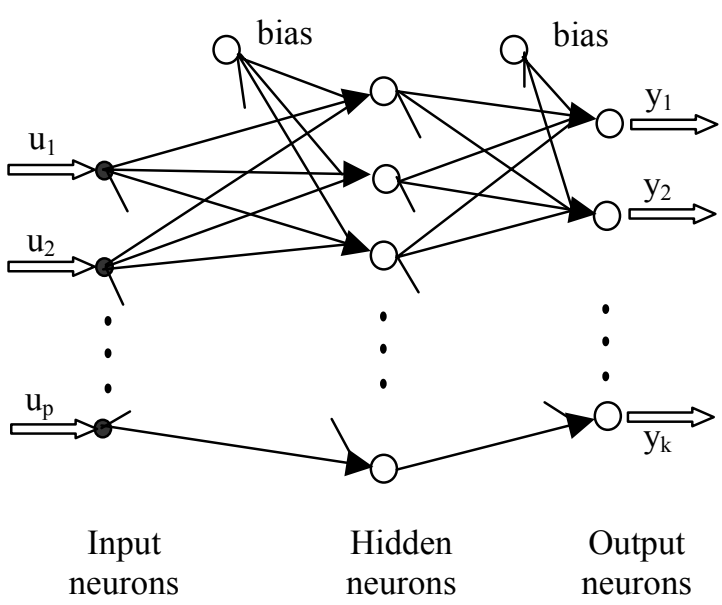

Fig. 4. Multi-layer perceptrons network.

Another task besides training is to select the optimal configuration of the ANN for a given problem, namely the smallest system that will fit the data. Although there are a few constructive and pruning methods for the selection of (near) optimal architectures, it is mostly done by a trial/error approach. Some interesting applications of multi-layer perceptrons for simulation can be found in [7], [23], [6] and [24].

Although radial basis function (RBF) networks have the same structural characteristics as MLPs (see Fig. 4), the processing of information in the hidden layer is different. Here, in each unit the response is calculated according to a multivariate Gaussian function that has two parameters, a centre in the input vector space and a spread. The result (y) is then obtained by a 
linear combination of the weighted outputs of the hidden layer. For a more detailed discussion see [21]:

The training process of RBFs consists of first choosing the radial basis centre and spread constants, and then adjusting the output weights. The training process is generally simpler than MLP training. However RBFs tend to require more neurons. For details the reader is referred to [21]. Some applications of RBFs can be found in [25-28].

\section{SIMULATION DESIGN}

As mentioned before, there are a large number of parameters affecting solar collector performance. In this work only the most relevant design and environmental factors were selected as inputs for both systems: solar radiation, ambient temperature, inlet gas temperature, inlet water temperature, evaporator length, condenser length, gas mass flow rate and water mass flow rate. Another independent variable was added in the plate heat pipe to characterise the collector condenser section geometry and flow: the heat transfer coefficient in the condenser section. In order to ensure that the ANN is properly trained, it is crucial that representative input/output data are selected for training.

The simulations were divided in two phases. First a Monte Carlo simulation was carried out using the energy balance models assuming uniform distribution for each input. Table 2 shows the lower and upper bounds considered for the factors. Random sampling was made using the Latin Hypercube technique, so that the sampling points cannot cluster together. Several hundreds of data were simulated for both solar collector designs. The dependent variables were the collector efficiency and the collector heat output. A similar approach can be found in [29].

Table 2. Range of the independent variables.

\begin{tabular}{|l|l|}
\hline $\mathrm{I}$ & $0-1000 \mathrm{~W} / \mathrm{m}^{2}$ \\
\hline $\mathrm{T}_{\mathrm{a}}$ & $5-30^{\circ} \mathrm{C}$ \\
\hline $\mathrm{T}_{\text {gas,in }}$ & $200-400^{\circ} \mathrm{C}$ \\
\hline $\mathrm{T}_{\mathrm{w}, \text { in }}$ & $30-90^{\circ} \mathrm{C}$ \\
\hline $\mathrm{I}_{\text {evap }}$ & $1.5-2 \mathrm{~m}$ \\
\hline $\mathrm{I}_{\text {cond }}$ & $0.04-0.10 \mathrm{~m}$ \\
\hline $\mathrm{m}_{\text {gas }}$ & $0.0025-0.02186 \mathrm{~kg} / \mathrm{s}$ \\
\hline $\mathrm{m}_{\mathrm{w}}$ & $0.005-0.05 \mathrm{~kg} / \mathrm{s}$ \\
\hline $\mathrm{U}$ & $2000-4000 \mathrm{~W} / \mathrm{m}^{2} /{ }^{\circ} \mathrm{C}$ \\
\hline
\end{tabular}

In the second phase, the optimal ANN architecture was selected and trained. The data was normalised and divided into three sets, at least 250 for training, 50 for validation and 50 for test. The validation data set is used for avoiding over-training by stopping the training process at the point where the validation MSE starts to increase. The test data is designated to evaluate the generalisation capabilities of the trained network ("unseen" data). For the selection of the best configurations, a commercial software, Statistica's (StatSoft, USA) Intelligent Problem Solver was used. For details the reader is referred to [30]. The best networks were then tuned at least 100 times by selecting random initial weights. It was necessary in order to avoid local minima on the error surface (Eq. 7). For the tuning process Matlab 6 (The Math Works,
USA) was used. The results obtained by the two types of models were compared using simple regression.

\section{RESULTS AND DISCUSSION}

More than six hundred cases were simulated using the regressive models described in section 3.1. The results are summarized in Table 3.

Table 3. Summary statistics of efficiency and heat flux.

\begin{tabular}{|l|l|l|l|l|}
\cline { 2 - 5 } \multicolumn{1}{c|}{} & \multicolumn{3}{|l}{$\begin{array}{l}\text { Tube heat pipe } \\
\text { collector }\end{array}$} & \multicolumn{2}{l}{$\begin{array}{l}\text { Plate heat pipe } \\
\text { collector }\end{array}$} \\
\cline { 2 - 5 } \multicolumn{1}{c|}{} & $\eta$ & $\mathrm{q}\left[\mathrm{W} / \mathrm{m}^{2}\right]$ & $\eta$ & $\mathrm{q}\left[\mathrm{W} / \mathrm{m}^{2}\right]$ \\
\hline $\begin{array}{l}\text { Number of } \\
\text { cases }\end{array}$ & 693 & 693 & 691 & 691 \\
\hline Maximum & 0.880 & 2990 & 0.986 & 2810 \\
\hline Minimum & 0.034 & 11.4 & 0.166 & 108 \\
\hline Mean & 0.657 & 1030 & 0.629 & 1060 \\
\hline $\begin{array}{l}\text { St. } \\
\text { Deviation }\end{array}$ & 0.123 & 531 & 0.154 & 456 \\
\hline
\end{tabular}

It was found that there were only small differences in the performance of the two collectors considering either the heat flux or the efficiency results. The difference was $3 \%$ and $4 \%$ for the heat flux and efficiency respectively, which is probably within the accuracy of the models. The standard deviation and minimum/maximum values indicated that, for the same set of input conditions, the tubular collector had a more equilibrated efficiency. However there was a smaller dispersion of the heat flux in the case of the plate heat pipe.

About $40 \%$ of the random combinations of the input data resulted in a divergent solution for the plate type collector. This value was slightly higher for the more complex model (tube type). However, there was no clear and simple evidence of what combination of the input values caused divergence.

In order to model the solar collector performance using ANNs, first the best configurations have to be selected. The training time for each case was less than a minute and fast convergence was obtained for all training situations. Once the network was trained, simulation was instantaneous. The best architectures, already tuned by retraining, with the corresponding MSE for both systems, are summarised in Table 4.

Table 4 MSE for several configurations.

\begin{tabular}{|l|c|c|l|c|c|}
\hline \multicolumn{3}{|l|}{ Tube heat pipe collector } & \multicolumn{3}{l|}{ Plate heat pipe collector } \\
\hline Model & MSE & q MSE & model & MSE & q MSE \\
\hline MLP 8-3-1 & 0.0028 & 0.0016 & MLP 9-3-1 & 0.0118 & 0.0054 \\
\hline MLP 8-5-1 & 0.0015 & 0.0007 & MLP 9-6-1 & 0.0131 & 0.0036 \\
\hline MLP 8-6-1 & 0.0011 & 0.0005 & MLP 9-9-1 & 0.0145 & 0.0042 \\
\hline MLP 8-9-1 & 0.0005 & 0.0002 & RBF 9-55-1 & 0.0420 & \\
\hline MLP 8-11-1 & 0.0011 & 0.0002 & RBF 9-84-1 & & 0.0079 \\
\hline RBF 8-83-1 & 0.0062 & 0.0050 & & & \\
\hline
\end{tabular}

The evaluation was based on the mean square error calculated for the test ("unseen") data set. Perhaps the most interesting result is that the best MLPs configurations needed only a few hidden neurons to simulate both the solar collector efficiency and heat flux. It was observed that although the mathematical model used to generate the target values was more 
complex for the tube type collector, the mean square error of the approximation was generally one order of magnitude smaller for the same ANN architecture compared to the plate type. In the case of the tube collector, the best accuracy was obtained with 9 hidden nodes for both $Q$ and $\eta$. For the plate type, a network with only 6 and 3 hidden neurons for the useful heat flux and efficiency gave the lowest MSE respectively. The performance with radial basis function is in general weaker. For RBF 9-84-1 the heat flux in plate heat pipe collector has a MSE about the double of magnitude of MLP models.

Figures 5 and 6 show observed (regressive model) versus predicted (neural network model) heat outputs in the plate heat pipe solar collector with the radial basis function (RBF 9-84-1) and multi-layer perceptron (MLP 9-6-1) that resulted in the lowest MSE.

There was a very good agreement between predicted and observed values for both cases. However the MLP models seem to perform slightly better. This better performance was indicated by the higher $R^{2}$ value (0.96 vs. 0.92$)$ as well as by the $95 \%$ confidence intervals calculated for the slope and intercept of the regression line which included 1 and 0 respectively. An important advantage of the MLP network is that it has less parameters than the optimal RBF configuration.

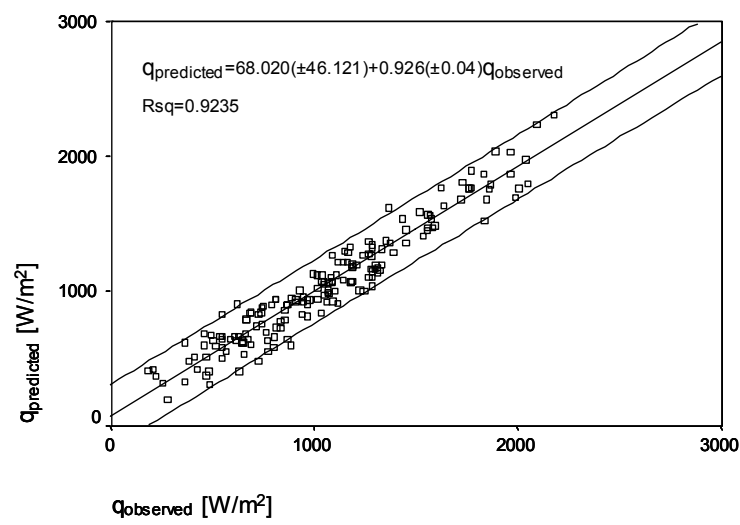

Fig. 5. Observed (regressive) versus predicted (neural network) collector heat output, for plate heat pipe solar collector with radial basis function model RBF 9-84-1.

Figures 7, 8 and 9 show the useful heat results for the tube heat pipe solar collector. As expected, the goodness of fitting in this case was higher than for the plate type collector. In comparison with the data obtained by the correlation model, the multi-layer perceptron network with 9 hidden neurons had a regression coefficient of nearly 1 (Fig. 8).

The confidence intervals for the estimated regression parameters indicated that 1 and 0 were included for the slope and intercept respectively. Only a somewhat smaller coefficient of correlation $\left(R^{2}=0.998\right)$ was obtained for the model with only 6 hidden neurons that was the optimal architecture for the plate type solar collector. As in the previous case, the values 1 and 0 were within the $95 \%$ confidence interval for the estimates of the slope and intercept of the regression parameters. Therefore, this configuration can be considered a good choice for simulating the useful heat for both systems. It was found that RBF networks performed slightly poorer than MLPs, but still providing an acceptable accuracy (Fig. 7).

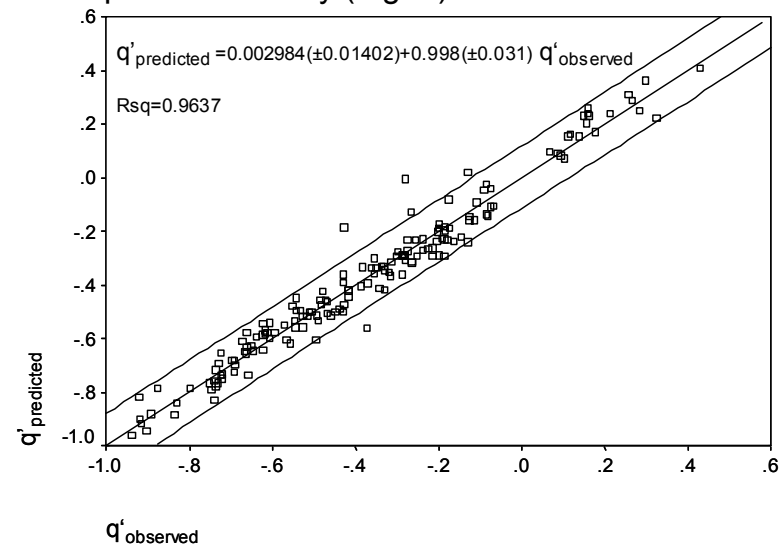

Fig. 6. Observed versus predicted collector heat output, for plate heat pipe solar collector with multi-layer perceptron model MLP9-6-1.

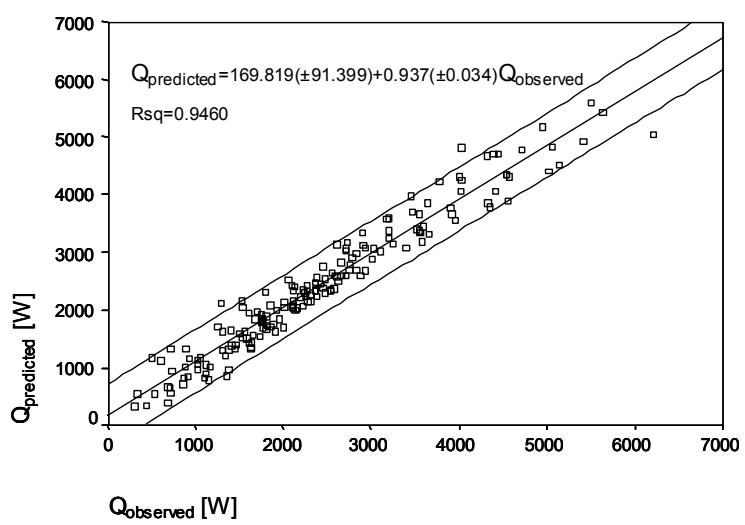

Fig. 7. Observed versus predicted collector heat output, for a radial basis function model with 83 hidden neurons in the tube heat pipe solar collector.

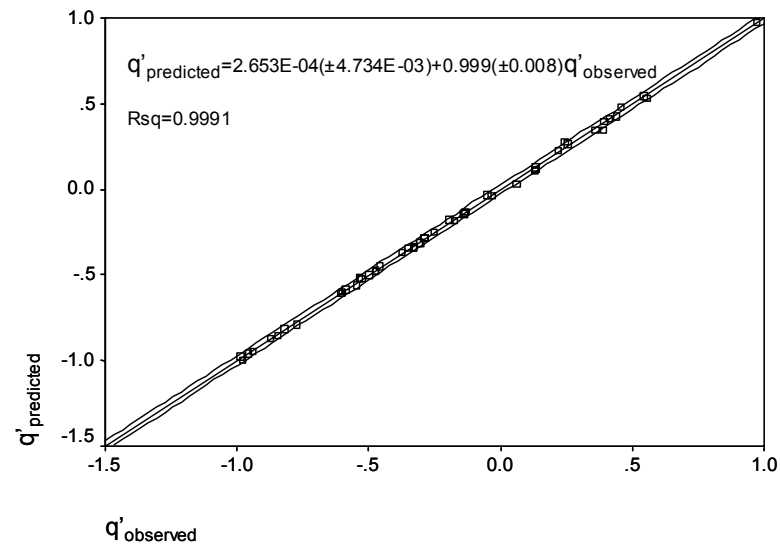

Fig. 8. Observed versus predicted collector heat output, for a multi-layer perceptron model with 9 hidden neurons in the tube heat pipe solar collector.

Analysing the results obtained for the normalised thermal efficiency, similar conclusions can be drawn. An MLP with 6 hidden neurons represents an atractive 
alternative for simulating a solar collector because of its simplicity, instantaneous response and because it did not present any convergence problem.

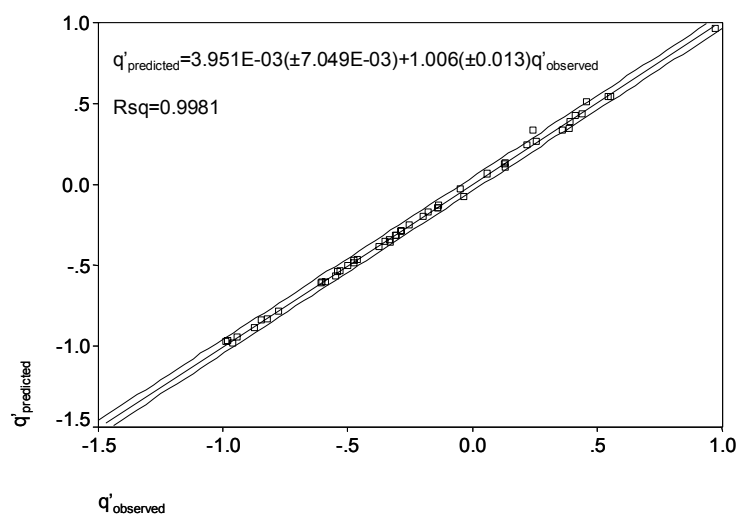

Fig. 9. Observed versus predicted collector heat output, for a multi-layer perceptron model with 6 hidden neurons in the tube heat pipe solar collector.

\section{CONCLUSIONS}

The use of neural networks for the simulation of the thermal performance of two types of heat pipe solar collectors was evaluated. The evaluation was based on the comparison with the results obtained by a traditional simulation (energy balance model), for a large variety of environmental and design conditions.

Convergence problems were observed in about $40 \%$ of the input combinations using the energy balance models. However, there was no clear evidence of what caused the divergence. Results indicated that there was only an insignificant difference between the two collector designs in terms of the average thermal efficiency and average heat flux transferred to the cooling liquid for the same set of conditions.

Two types of feed forward ANN models were found to be useful for the simulation of the two systems: MLP and RBF. Besides being simpler, multiple layer perceptrons performed slightly better than radial basis function networks. Several configurations were tested and it was found that the MLP configuration with 6 hidden neurons provided an excellent alternative to calculate useful heat and thermal efficiency for both designs. It can be concluded that ANNs have several advantages over the energy balance based models, such as: instantaneous response, no convergence problem, insensitivity to uncertainties in the input parameters, simple structure (small number of weights) and high accuracy.

\section{Acknowledgement}

The authors wish to thank Fundação para a Ciência e a Tecnologia, for the scholarship of the first author.

The work was developed within the framework of the HYBRID-CHP project, which was funded by the Commission of European Communities, through the Energy, Environment and Sustainable Development programme, contract ENK5-CT2000-0080. The other partners of this project are also acknowledged.

\section{NOMENCLATURE}

C space between two tubes $(\mathrm{mm})$

$d_{\text {ext }} \quad$ external tube diameter $(\mathrm{mm})$

$d x \quad$ differential length between tubes $(\mathrm{m})$

$c_{p} \quad$ specific heat $(\mathrm{J} / \mathrm{kg} / \mathrm{K})$

$F \quad$ activation function

$h$ convection heat transfer coefficient $\left(\mathrm{W} / \mathrm{m}^{2} / \mathrm{K}\right)$

I incident solar radiation on tilted collector surface $\left(\mathrm{W} / \mathrm{m}^{2}\right)$

I length (m)

MSE mean square error

$m$ mass flow rate $(\mathrm{kg} / \mathrm{s})$

$n \quad$ number of cases

$\mathrm{Np} \quad$ total number of training patterns

$n_{s} \quad$ number of neurons in the output layer

$p \quad$ input connections

$q \quad$ heat flux $\left(\mathrm{W} / \mathrm{m}^{2}\right)$

q' normalised heat flux

$Q \quad$ heat flux (W)

$Q^{\prime} \quad$ heat flux per unit length of heat pipe $(\mathrm{W} / \mathrm{m})$

$R_{\text {heatpipe }}$ heat pipe thermal resistance $(\mathrm{W} / \mathrm{m} / \mathrm{K})$

$S$ absorbed solar radiation $\left(\mathrm{W} / \mathrm{m}^{2}\right)$

$T$ temperature $\left({ }^{\circ} \mathrm{C}, \mathrm{K}\right)$

$t_{\text {ip }} \quad$ target

$u \quad$ input variable

$U$ heat transfer coefficient in the condenser section $\left(\mathrm{W} / \mathrm{m}^{2} \mathrm{~K}\right)$

w weight

y output variable

$y_{i p} \quad$ observed value

\section{Greek Letters}

$\delta \quad$ plate thickness (mm)

$\varepsilon \quad$ emissivity

$\eta_{\text {collector }} \quad$ collector thermal efficiency

$\lambda$ thermal conductivity $(\mathrm{W} / \mathrm{m} / \mathrm{K})$

$\sigma \quad$ Stefan-Boltzmann constant $\left(\mathrm{W} / \mathrm{m}^{2} / \mathrm{K}^{4}\right)$

\section{Subscripts}

$\begin{array}{ll}\text { a } & \text { ambient } \\ c & \text { cover } \\ c 1 & \text { cover 1 } \\ \text { cond } & \text { condenser } \\ \text { evap } & \text { evaporator } \\ \text { gas } & \text { gas } \\ \text { in } & \text { inlet } \\ \text { out } & \text { outlet } \\ p & \text { plate } \\ p-c 1 & \text { plate to cover } 1 \\ t & \text { tube } \\ w & \text { water }\end{array}$

\section{REFERENCES}

1. J. Ribot and R. D. McConnell, Testing and analysis of a heat pipe solar collector, Journal of Solar Energy Engineering, Transactions of the ASME 105, 440-445, (1983).

2. T. Y. Bong, K. C. Ng and H. Bao, Thermal performance of a flat-plate heat-pipe collector array, Solar Energy 50 (6), 491-498, (1993).

3. S. B. Riffat, P. S. Doherty and E. I. Abdel Aziz, Performance testing of different types of liquid flat 
plate collectors, International Journal of Energy Research, 24, 1203-1215, (2000).

4. K. A. R. Ismail and M. M. Abogderah, Performance of a Heat Pipe Solar Collector, Journal of Solar Energy Engineering, Transactions of the ASME 120, 51-59, (1998).

5. Emmanouil Mathioulakis and Vassilis Belessiotis, A New Heat-Pipe Type Solar Domestic Hot Water System, Solar Energy 120 (1), 13-20, (2002).

6. S. A. Kalogirou and S. Panteliou, Thermosiphon solar domestic water heating system: long-term performance prediction using artificial neural networks, Solar Energy 69 (2), 163-164 (2000).

7. M. Sen and K. T Yang., Applications of artificial neural networks and genetic algorithms in thermal engineering, in: F. Kreith (Ed.), CRC Handbook of Thermal Engineering, 2000, pp. 620-661 (Section 4.24).

8. Soteris A Kalogirou., Artificial neural networks in renewable energy systems applications: a review, Renewable and Sustainable Energy Reviews 5, 373-401, (2001).

9. "Hybrid-CHP - An Hybrid Combined Heat and Power System" EU Research Contract $n^{\circ}$ ENK5CT-2000-0080.

10. Jorge Facão, Szabolks Varga and Armando C. Oliveira, Neural networks as alternative to evaluate the performance of hybrid heat pipe solar collectors, submitted to the journal Neural Networks, Elsevier Science.

11. K. G. T. Hollands, T. E. Unny, G. D. Raithby and L. Konicek , Free Convection Heat Transfer Across Inclined Air Layers, Trans. ASME, J. Heat Transfer, 98 (189) (1976)

12. E. M. Sparrow, J. W Ramsey. and E. A. Mass, Effect of Finite Width on Heat Transfer and Fluid Flow About an Inclined Rectangular Plate, Trans. ASME , J. Heat Transfer, 101 (2) (1979).

13. S.C Chapra and R.P. Canale, Numerical Methods for Engineers, 2nd ed. Mc Graw Hill, New York, 1989.

14. P. D. Dunn and D. A. Reay, Heat Pipes, Pergamon, fourth edition, 1993.

15. G. P. Peterson, An Introduction to Heat Pipes, Modelling, Testing, and Applications, John Wiley \& Sons, Inc., 1994.

16. F. W. Dittus and L. M. K. Boelter, Univ. Calif., Berkeley, Publ. Eng. 2:443(1930).

17. A. Zhukauskas, Heat Transfer from tubes in Cross Flow, in Advances in Heat Transfer, edited by $\mathrm{J}$. Eds., volume 8, Academic Press, New York, 1972.

18. S. A. Klein and F. L. Alvarado (2002). Engineering Equation Solver. F-Chart Software, Middleton, USA.

19. C. Looney, Pattern Recognition Using Neural Networks, Oxford University Press, NY, 1997.

20. R. D. Reed and R. J. Marks, Neural Smithing, MIT Press, Cambrige, 1999.

21. F.M Ham and I. Kostanic, Principles of Neurocomputing for Science and Engineering, McGraw-Hill, New York, 2001.
22. Howard Demuth, Neural network toolbox for use with Matlab, user's guide, version 4, The Math Works, 2000.

23. Arturo Pacheco-Vega, Mihir Sen, K. T. Yang and Rodney L. McClain, Neural network analysis of fintube refrigerating heat exchanger with limited experimental data, International Journal of Heat and Mass Transfer, 44 (2001) 763-770.

24. Y. Keymmoku, S. Orita, S. Nakagawa and T. Sakakibara, Daily Insolation Forecasting Using a Multi-Stage Neural Network, Solar Energy, vol. 66, No.3, pp. 193-199, 1999.

25. M. Mohandes, A. Balghonaim, M. Kassas, S Rehman and T. O. Halawani, Use of Radial Basis Functions for Estimating Monthly Mean Daily Solar Radiation, Solar Energy, vol. 68, No. 2, pp. 161168, 2000.

26. H. Bechtler, M. W. Browne, Bansal P. K. and Kecman V., New approach to dynamic modelling of vapour-compression liquid chillers: artificial neural networks, Applied Thermal Engineering 21 (2001) 941-953.

27. A Sfetsos and A.H Coonick, Univariate and multivariate forecasting of hourly solar radiation with artificial intelligence techniques. Solar Energy 68 (2) 169-178 (2000).

28. J. E. Hurtado, Analysis of one-dimensional stochastic finite elements using neural networks, Probabilistic Engineering Mechanics 17, 35-44 (2002).

29. M. Y. Rafiq, G. Bugmann and D. J. Easterbrook, Neural network design for engineering applications, Computers and Structures 79, 1541-1552 (2001).

30. StatSoft, Inc. (2001). User manual STATISTICA (data analysis software system), version 6 . www.statsoft.com. 